\title{
One year of paste operations at Jabal Sayid, Saudi Arabia
}

\author{
R Brown Paterson \& Cooke, Canada \\ N Smith Ma'aden Barrick Copper Company, Saudi Arabia \\ P Carmichael Ma'aden Barrick Copper Company, Saudi Arabia
}

\begin{abstract}
It took five years to bring mining with paste backfill to Ma'aden Barrick Copper Company's (MBCC) Jabal Sayid Mine in Saudi Arabia. The work involved various studies, multiple test programs, site visits for benchmarking and detailed engineering before the paste system was commissioned in October 2017. Barrick is a world leader in paste backfill and drew on international teams to conceptualise, design and construct this $225 \mathrm{~m}^{3} / \mathrm{hr}$ cemented paste backfill system. Value engineering, peer reviews and risk management workshops were held throughout the process to ensure MBCC received value for money and a reliable system.

The paste plant was required to handle a tailings stream that was originally planned to produce hydraulic fill (the coarse fraction) but through the reintroduction of fine tailings was able to generate a good paste product that met mining needs. Challenges involved getting the most out of the tailings dewatering circuits (both fine and coarse streams), the local conditions (temperatures $>50^{\circ} \mathrm{C}$ ), large bulk stopes fed by a gravity system and the capital cost associated with building a high throughput system with significant cement storage.

This paper presents the history of the project, test work, engineering design and construction, commissioning, and training required to fill the first stope. More recent backfill monitoring, data logging, improvements and ongoing optimisation of the system that have continued through the first year of paste production are also presented.
\end{abstract}

Keywords: paste, mining, backfill, operations, commissioning, reticulation, start-up

\section{Introduction}

With Saudi Arabia looking to transform its economy, the domestic mining industry is a key focus and set for the growth that comes from the development of large-scale, world-class operations (Ellyatt \& Gamble 2018). Ma'aden Barrick Copper Company's (MBCC) Jabal Sayid is the first of these operations, successfully leveraging Barrick's extensive global mining expertise and Ma'aden's history of mining operations within the Saudi kingdom. The operation's location, two hours by road southeast of Medina (Figure 1), has Jabal Sayid positioned in a challenging region environmentally, logistically and culturally, demanding practical solutions to difficult problems.

Jabal Sayid operates as an underground sub-level open-stoping operation where MBCC has endeavoured to implement a modern backfill system over the past five years to allow maximum recovery of the volcanogenic massive sulphide (VMS) deposit through pillarless mining. The key motivation of the system was to achieve production rates while confidently controlling the risks historically associated with underground backfill such as inrush, backfill failure during stoping, dilution and liquefaction. 


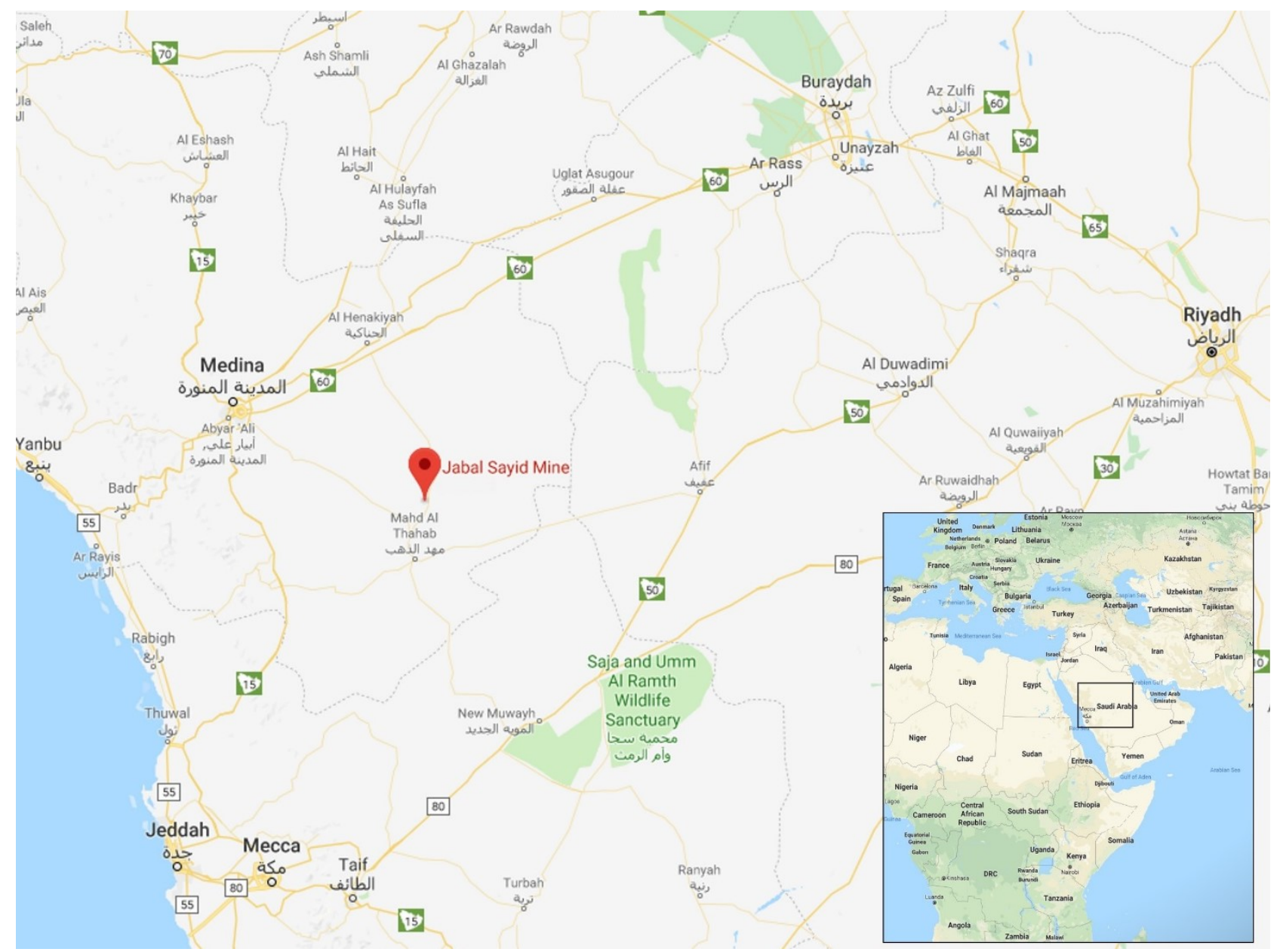

Figure 1 Jabal Sayid Mine location, Saudi Arabia. The Jabal Sayid project is located in the Kingdom of Saudi Arabia, $400 \mathrm{~km}$ northeast of Jeddah. Temperatures in the summer reach $54^{\circ} \mathrm{C}\left(129^{\circ} \mathrm{F}\right)$ with annual rainfall of less than $80 \mathrm{~mm}$

\section{$2 \quad$ Early studies and benchmarking}

The earliest studies were conducted internally by Barrick and supported by AMC Consultants and Rheological Consulting Services. A cemented paste fill was selected as the backfill of choice due to its strength properties, suitable rheology and use of the full tailings stream. The project team benchmarked against other paste mines and included visits to Sandfire Resources' DeGrussa Mine in Australia. Barrick's history and experience with paste from other mines like Goldstrike and Hemlo were incorporated into the process design and equipment selection. The visits gave the project team the opportunity to investigate plant sizing and throughput, equipment, maintenance and operating data.

Test work covered material characterisation, strength development and rheology. The tailings made a suitable paste with favourable rheology and strength gain. Figure 2 presents the particle size distribution (PSD) for the received tailings samples (coarse and fines) and the final blend, while Figure 3 presents the rheology. The Jabal Sayid tailings, when combined at a 56:44 fine to coarse ratio, made a stable paste backfill that did not demonstrate segregation or significant water bleed over time. The coarse tailings on their own, however, did not demonstrate paste behaviour as supported by the lack of fines $(-20 \mu \mathrm{m})$ content. The fine and coarse tailings are comprised mostly of quartz and chlorite. 


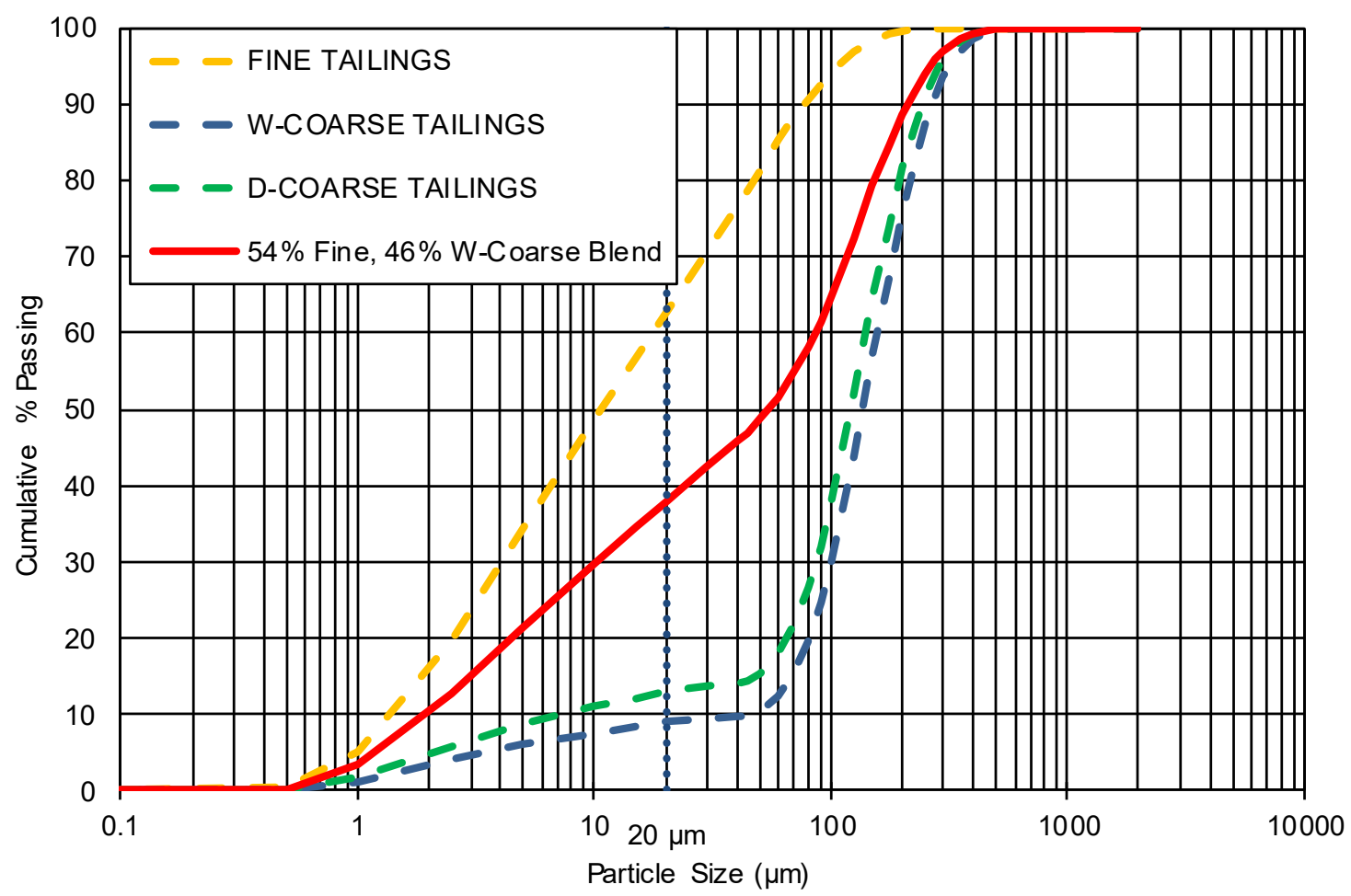

Figure 2 Final blend showing 54\% fine tailing and $46 \%$ coarse tailing blend particle size distribution

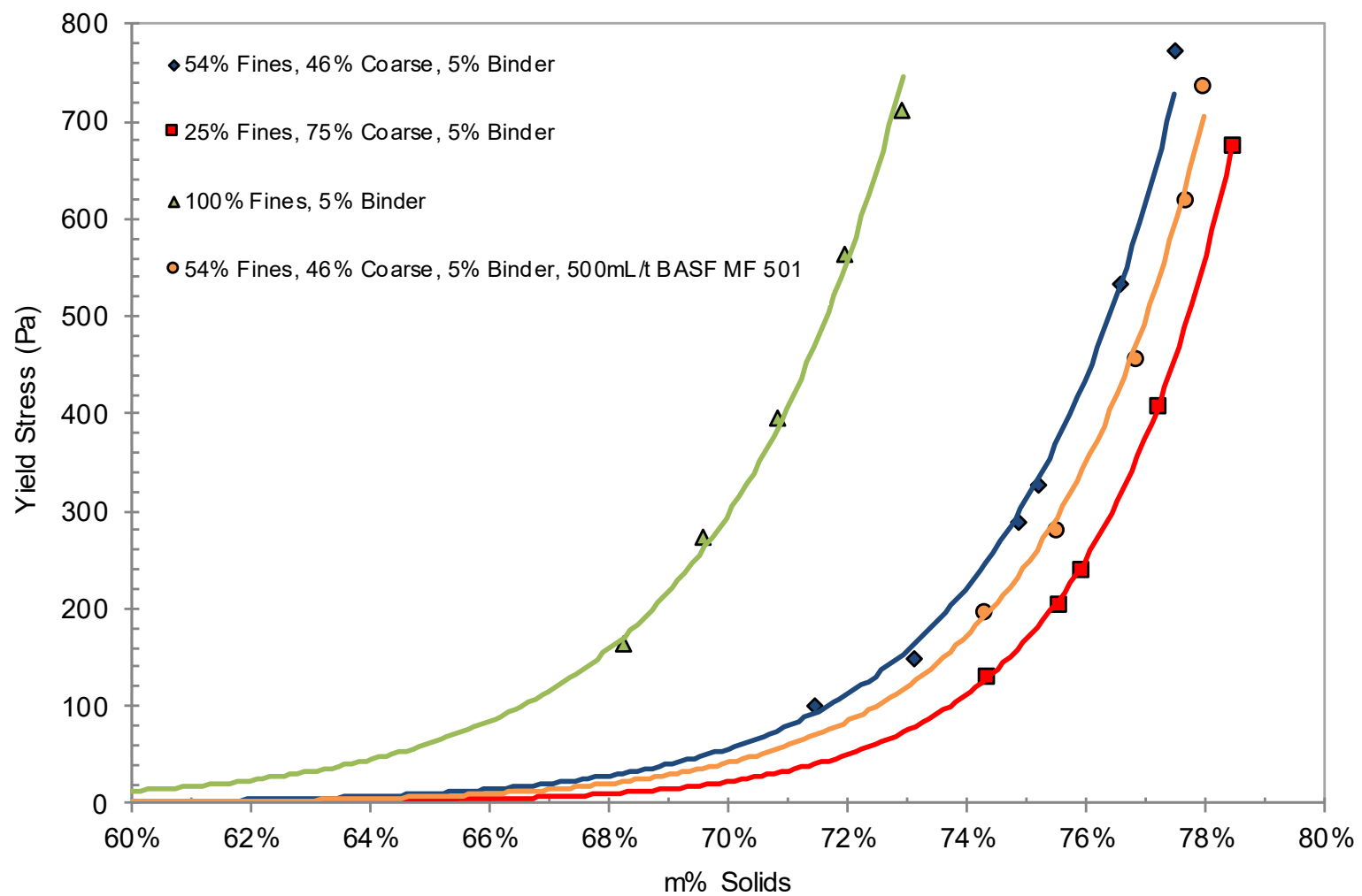

Figure 3 Static yield stress versus solids content for all rheology mixes 


\section{$3 \quad$ Basic and detailed engineering}

Barrick relied on internal paste resources to develop the concept and retained GR Engineering for the basic and detailed design. Paterson \& Cooke (P\&C) were drawn on to provide consultation on the initial plant design, complete laboratory testing, backfill design, document development, commissioning support, operator training and ongoing operational support for the backfill system. The flow sheet went through several iterations, some early ones based on conveying filter cake long distances. As the capital and operating cost estimates were refined, the long conveyors were replaced with trucking of filter cake from the mill to the paste plant. The final simplified flow sheet for the plant is presented in Figure 4.

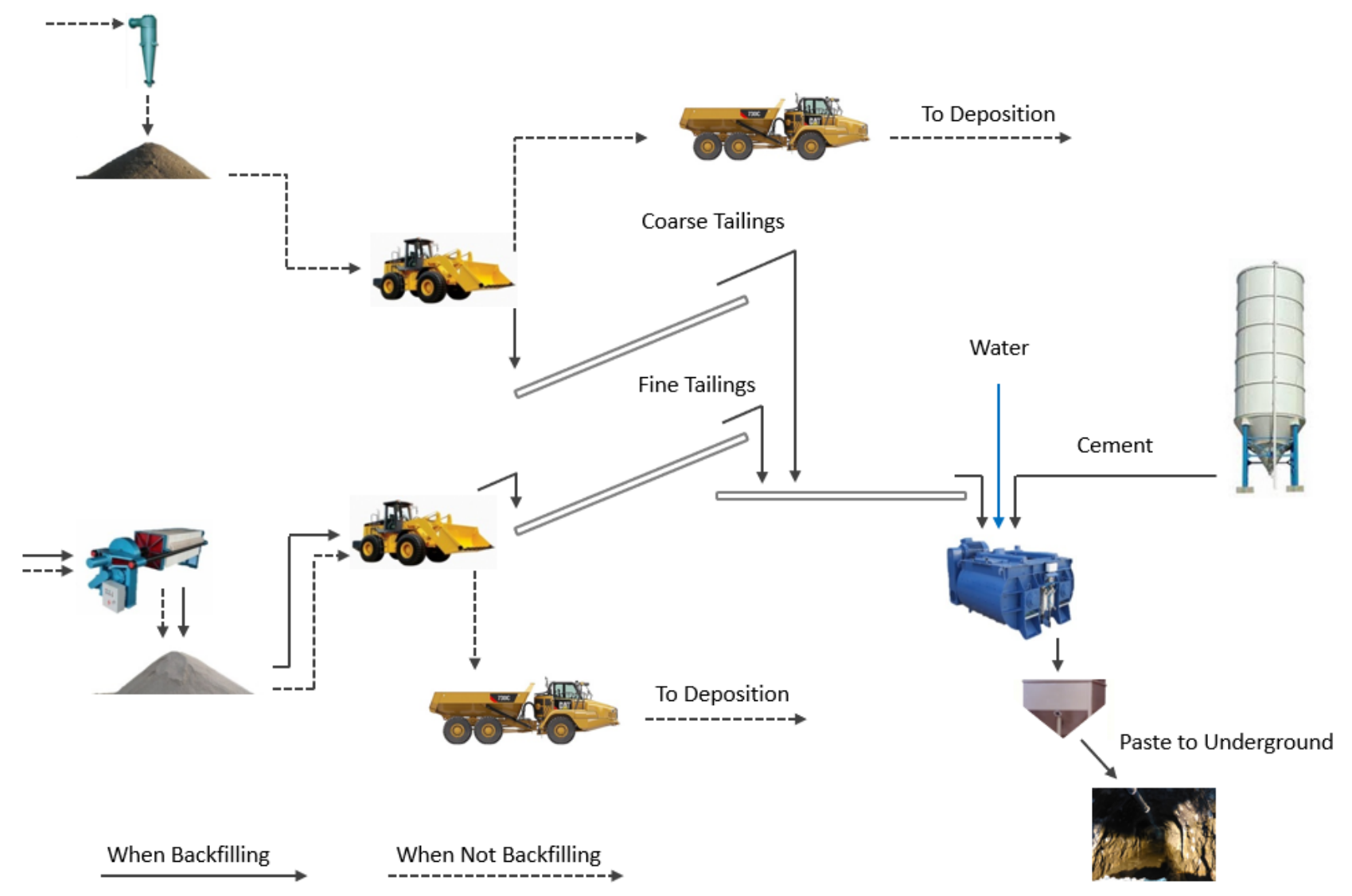

Figure 4 Simplified paste process flow sheet

The local economics, in a place where water costs more than fuel, made the study team revaluate previous stigmas about trucking and moisture content in tailings. In the end, the basic strategy evolved around recovering the most water out of the tailings as soon as possible. Trucking operations were already planned for the tailings storage plan, and so the route was deflected to carry filtered tailings to the paste plant on an as-required basis (Figure 5). Future considerations may be given to pumping of slurried tailings, but the current plan remains with the trucking filter cake option. 


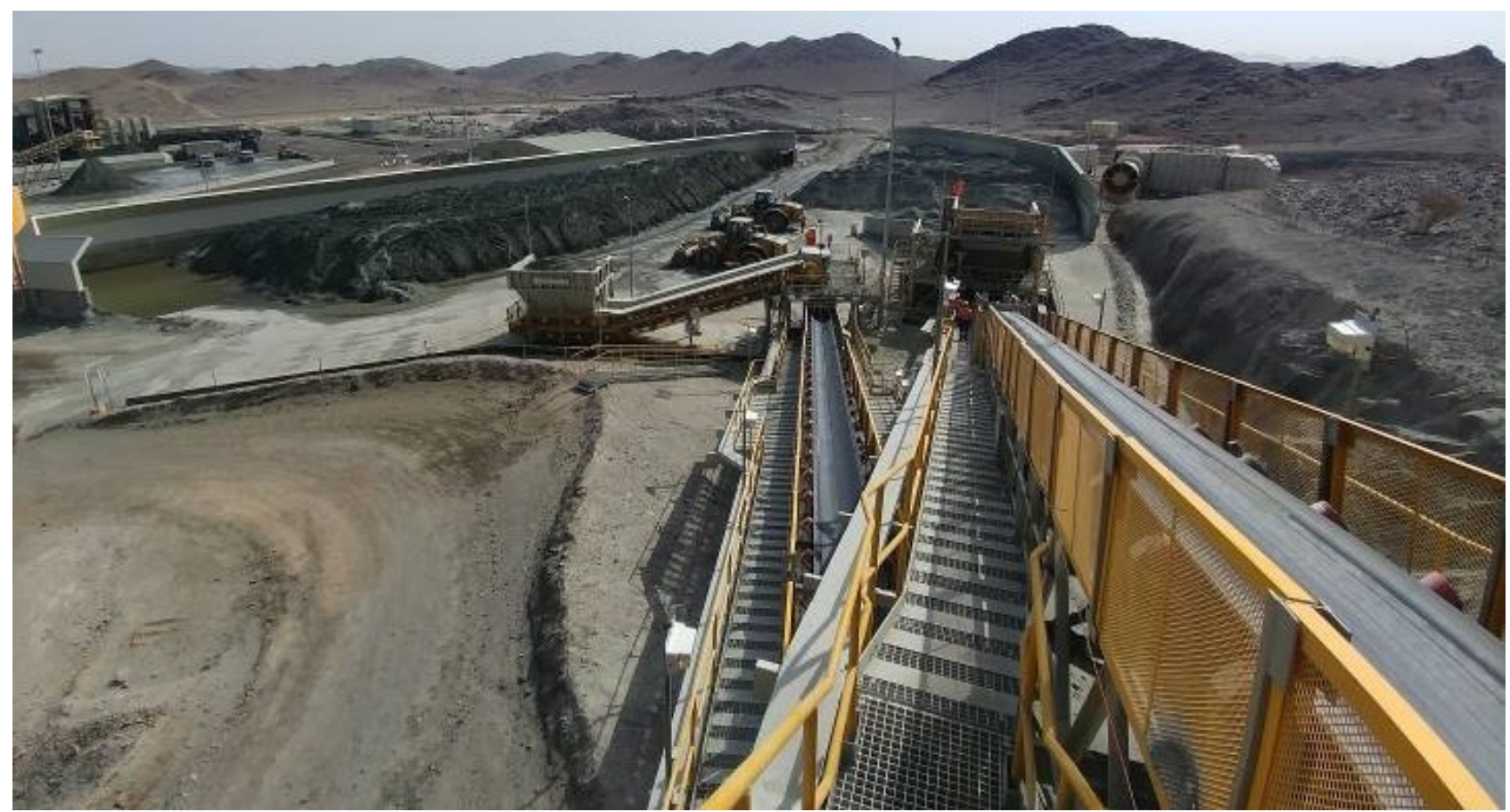

Figure 5 Paste plant tailings storage, feeders and conveyors (coarse left and fines right)

\section{$4 \quad$ Start-up}

With assistance from P\&C's paste engineers, Jabal Sayid moved from the end of construction through commissioning to full-scale production in the space of about six months. The entire team was under significant pressure to get tonnes underground and take over the temporary cemented rockfill operation. The mill had been running for months with filtered tailings directed to the tailings storage area and operations were under pressure to get cemented tailings underground.

\section{$5 \quad$ Water and tailings}

The most significant environmental challenge at Jabal Sayid is water scarcity. As no surface or groundwater is available, a fleet of $100+$ trucks per day haul water from a treatment facility in Medina, $250 \mathrm{~km}$ to site. As water recycling is critical, Jabal Sayid uses a dry tailings storage facility (TSF). The tailings stream from the processing plant is separated into two streams: the cyclone underflow which is dewatered on a sand stacker (once earmarked for hydraulic fill); and the cyclone overflow reporting to pressure filters to recover process water and provide the fines portion at a high-solids concentration needed for paste. The two streams are then stored separately at the TSF for recombination at the paste plant. This separation introduces unique challenges, including ensuring the correct tailings report to the correct feeders at the paste plant, maintaining the correct PSD through tailings blend ratios and ensuring foreign objects do not enter the tailings during the hauling and storage process to and from the TSF. This foreign material poses a risk of equipment damage and line blockage if allowed to enter the paste plant and into the underground reticulation.

These issues are not typical in the more common wet tailings feed paste plants where the full tailings stream is pumped directly to slurry tanks at the paste plant. One benefit of the dry tailings is providing the paste engineer with the ability to alter the paste PSD through changes in the ratio of addition of coarse and fine tailings. PSD variations can have significant effects on paste strength and rheology. Through the project reviews, $P \& C$ identified the risks involved with manually recombining tailings streams and recommended a laser particle size analyser in the paste plant to closely monitor the feed and product PSD. Using the particle analyser directly onsite has allowed tracking of the feed PSD by the national operators and has been incorporated into the routine quality assurance and quality control (QA/QC) process onsite. 


\section{$6 \quad$ Underground delivery}

With a nominal design flow rate of $225 \mathrm{~m}^{3} / \mathrm{hr}$, P\&C designed the paste reticulation system (Figure 6) to be gravity-driven and made up of 10 -inch $(25.4 \mathrm{~cm})$ schedule 80 ceramic lined casing, 8-inch schedule 80 trunk piping with Victaulic pipe couplings and 10-inch PN16 high-density polyethylene (HDPE) stope piping. Diversion valves and friction loops are used to manage the flow underground. Pressures are logged continually, and the data is used to flag changes in flow behaviour and to model delivery to future stopes.

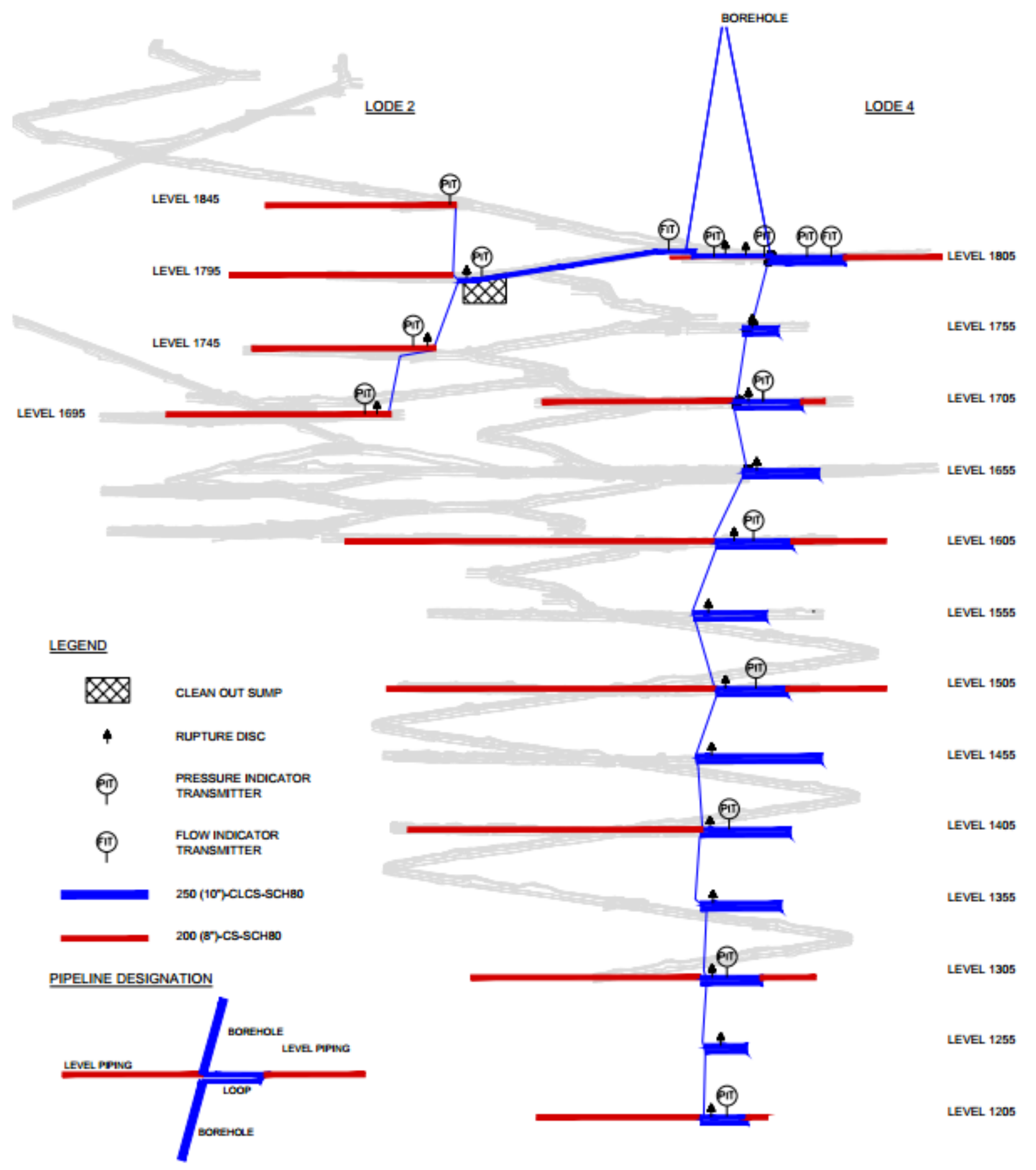

LEVEL 1155 
Engineering solutions in the paste plant and underground reticulation system were pivotal in the success of commissioning, including the several engineering controls that were installed. These included a high-pressure water flush pump, paste hopper and reticulation dump valves, an underground reticulation pressure sensor network, underground flow meter, paste pour point closed circuit television (CCTV) camera network (Figure 7), live barricade monitoring through the NEWTRAX program and reticulation blockage/overpressure relief options. MBCC implemented these controls to ensure success of the paste fill system by providing maximum live information feedback to the paste plant operators to make decisions and develop their skills and knowledge base.

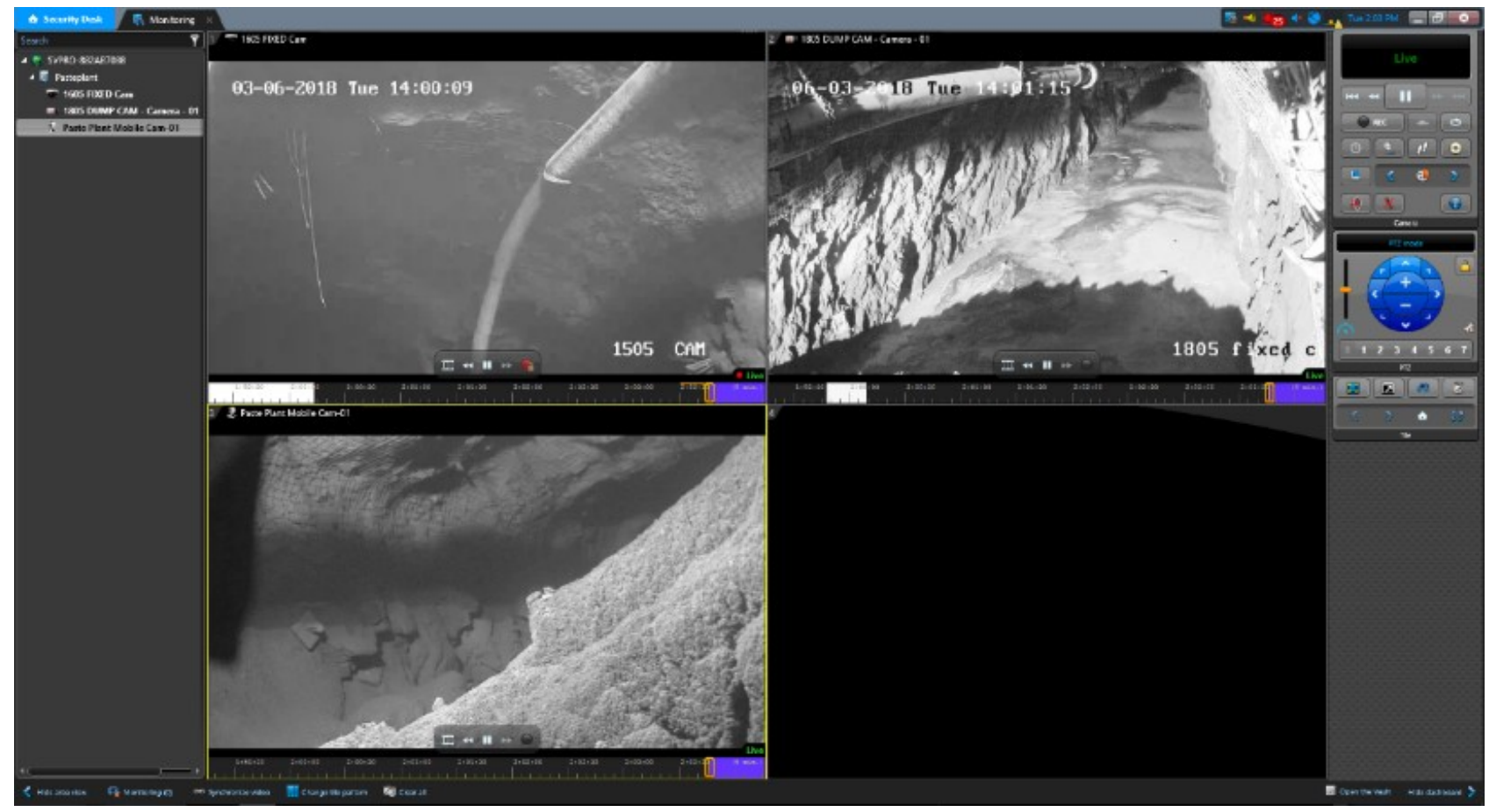

Figure 7 Live camera feed from typical paste pour at Jabal Sayid

For example, the high-pressure water pump with the ability to flush the reticulation at 3,500 kPa (instead of typical plant air of $700 \mathrm{kPa}$ ) has provided a significant buffer for operator inexperience. During commissioning, operator error due to inexperience would have seen several line blockages without the pump installation, causing significant production delays. The implementation of these controls, albeit at a significant cost, have cemented the value of designing a custom system. Such a system is not focused solely on the feed materials and the product but considers the operating environment and future cost to the business of downtime and capital underperformance.

Barricade design and monitoring (Figure 8) were completed by Mine Design Engineering and the upfront engineering has been worthwhile as it provided a conservative baseline for the confident construction of barricades and allowed rigorous back-analysis from underground monitoring data. The feedback and back-analysis of underground data has allowed the mine to develop a growing database of representative information and commenced continuous filling within the first year of operation. 

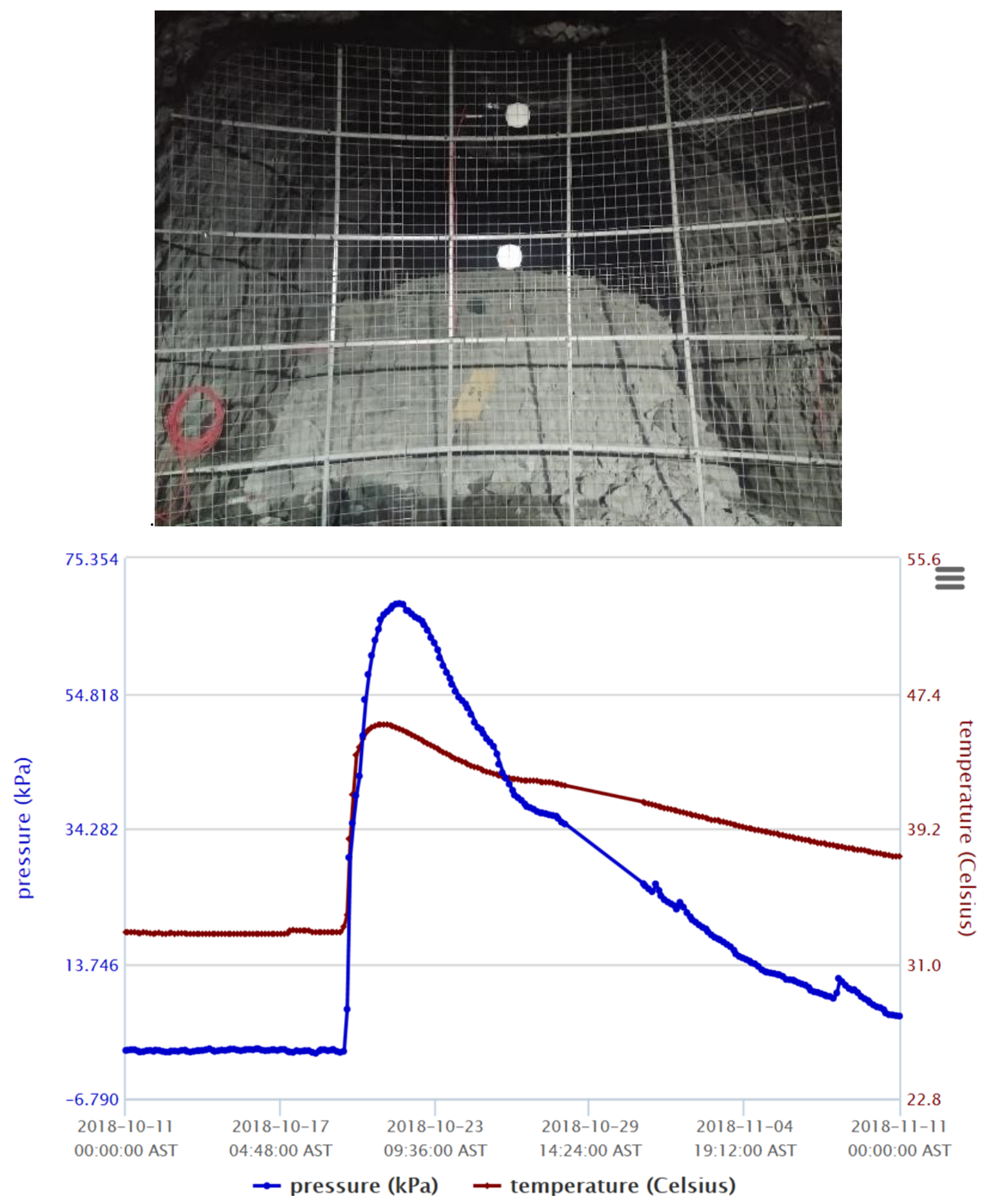

Figure 8 Paste barricade under construction and continuous monitoring 
A total of eight stope barricades were used as part of the continuous fill analysis, incorporating top and bottom pressure cell data (compared against design capacity of $200 \mathrm{kPa}$ ), 1-day and 3-day strength data (achievement of the non-liquefaction point of $100 \mathrm{kPa}$ ), and various stope geometries (various rates of rise). The pressure data for one of these barricades is presented in Figure 9.

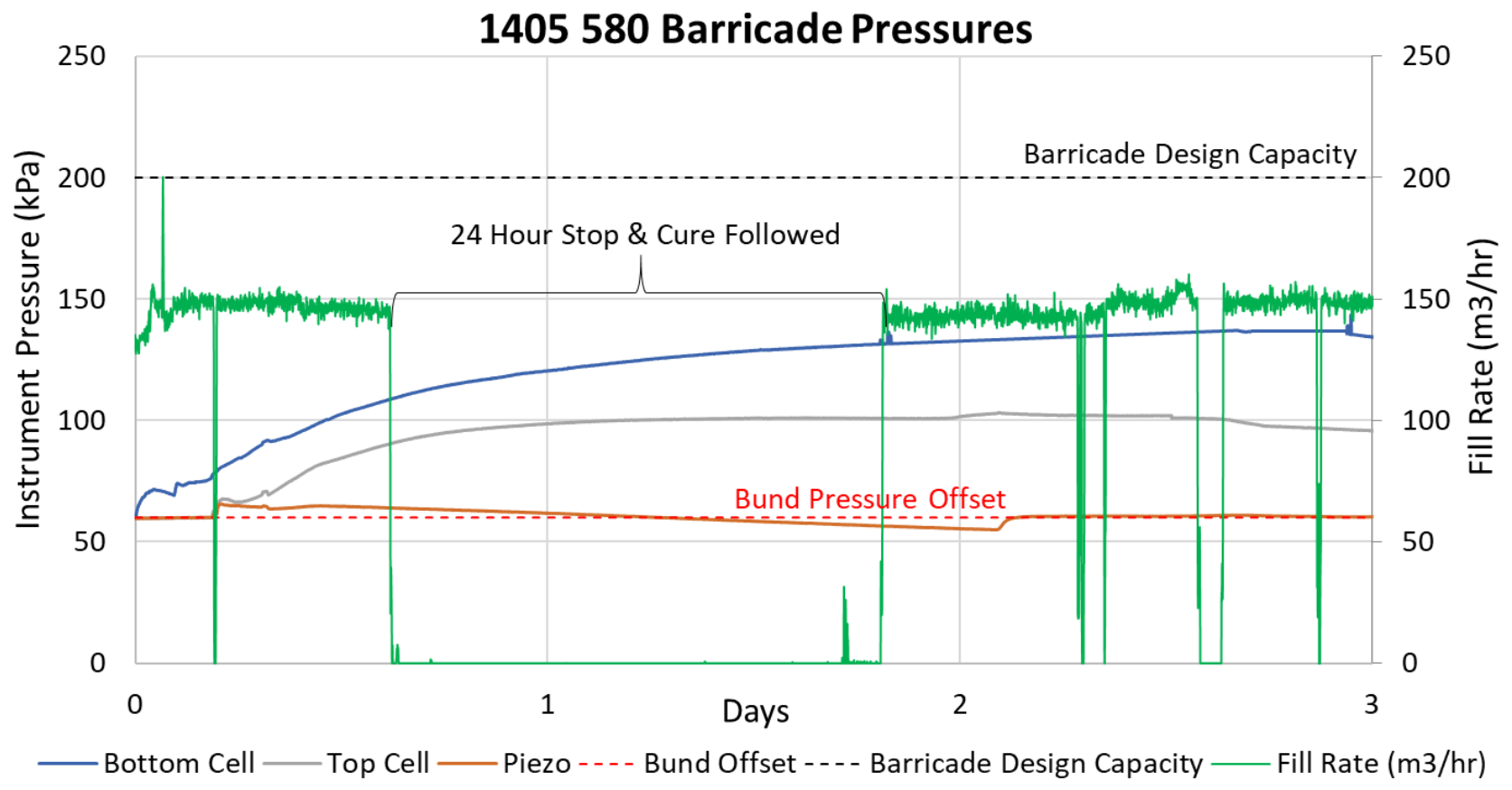

Figure 9 Continuous fill justification (single stope example)

The operation enlisted the expertise of chemical company BASF to design the shotcrete recipe for the paste barricades and provided the training to a local supplier that delivers batches on demand, eliminating the challenges of managing shotcrete production onsite. Quality control of the applied product is carried out in-house using the Hilti Nail Gun method to ensure the design strength of $20 \mathrm{MPa}$ is achieved within 24 hours of application.

\section{$7 \quad$ Skilled labour}

As the first backfill plant in the Saudi kingdom, an international team was employed to conceptualise the design and construct the $225 \mathrm{~m}^{3} / \mathrm{hr}$ plant and underground reticulation system, though all operating is undertaken by national employees. With no experienced backfill operators and minimal processing plant experience available locally, the national team operated the plant through commissioning with minimal training and paste background knowledge. Along with inherent language barriers, this challenge was managed safely through several methods. For example, methods such as selecting the most experienced process plant operators, training them on the QA/QC procedures in a temporary lab fitted with the delivered lab equipment (while the plant was being constructed) and taking the operators underground (Figure 10) to see the infrastructure and the route their paste would take, were essential in developing the initial understanding of the effects of PSD on flowability of paste and an appreciation of the time it takes to react during flushing. 


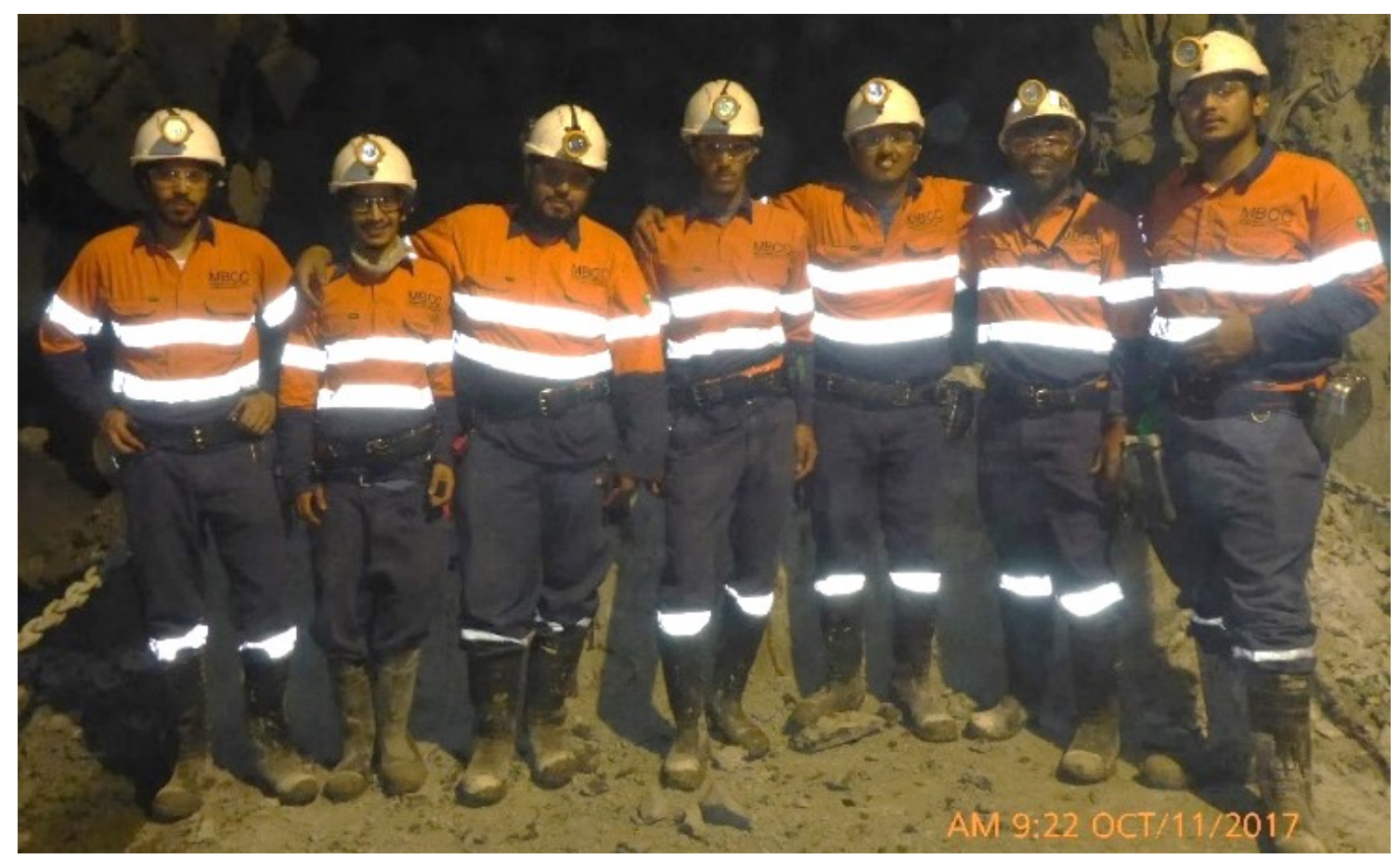

Figure 10 Jabal Sayid paste operators and supervisor underground

From a personnel management perspective, close supervision and training, initially by $\mathrm{P} \& \mathrm{C}$ paste engineers and later full-time experienced expatriate engineers, was key to the success of the commissioning process. Along with day shift-only paste fill for the first two months, maintaining supervision, training and onsite incident response ability during all filling, the plant achieved sustained full production rates in about three months.

Through commissioning, test-pours and now full-scale operations, the live feedback provided to the operators through the multiple monitoring systems has helped develop confidence and understanding, while reinforcing the effect their decisions have on the strength, rheology, delivery and overall behaviour of the paste fill, ultimately setting them up for success as competent paste plant operators.

\section{Challenges}

As with every new process or start-up, challenges develop and must be dealt with in the field. Managing the feed materials, particularly the pressure filtered fine tailings cake, was difficult (as expected), and took several iterations to improve the quality and reliability of the feed. Dry fine tailings filter cake lends itself well to lumps (like balls of clay, Figure 11) and these have had to be managed in the process. The live bottom feeder was first modified with a deflector plate to manage the impact of bucket loads on the shafts and to disperse the fine cake across all shafts and blades. Drying the fine cake further through desiccation onsite also helped weaken the lumps and improved their breakup in the mixing process. Currently, the fine cake is transported to the TSF for drying before being transported back to the paste plant. Plans are underway to install vibrating screens on both the coarse and fines hoppers to help contain lumps and capture foreign material (Figure 12) that has found its way into the tailings stockpiles. A more optimised method of drying the fines cake is also being investigated to reduce the amount of trucking currently required. 


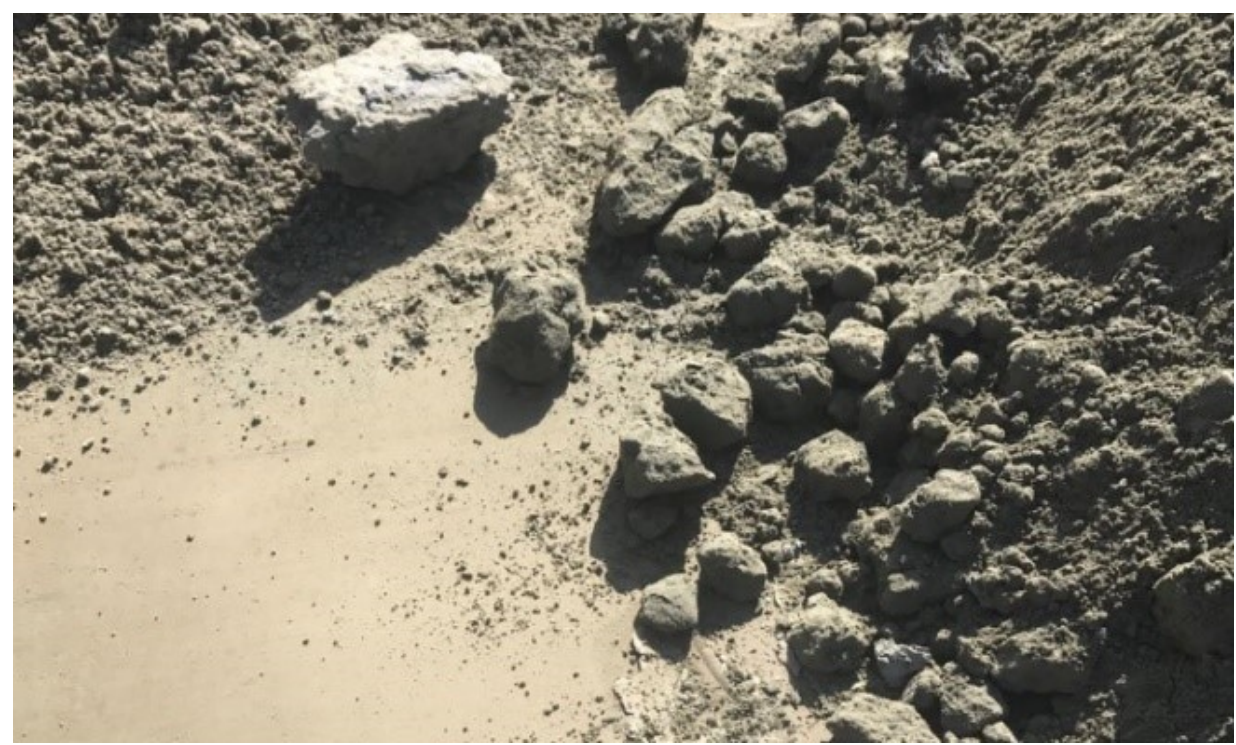

(a)

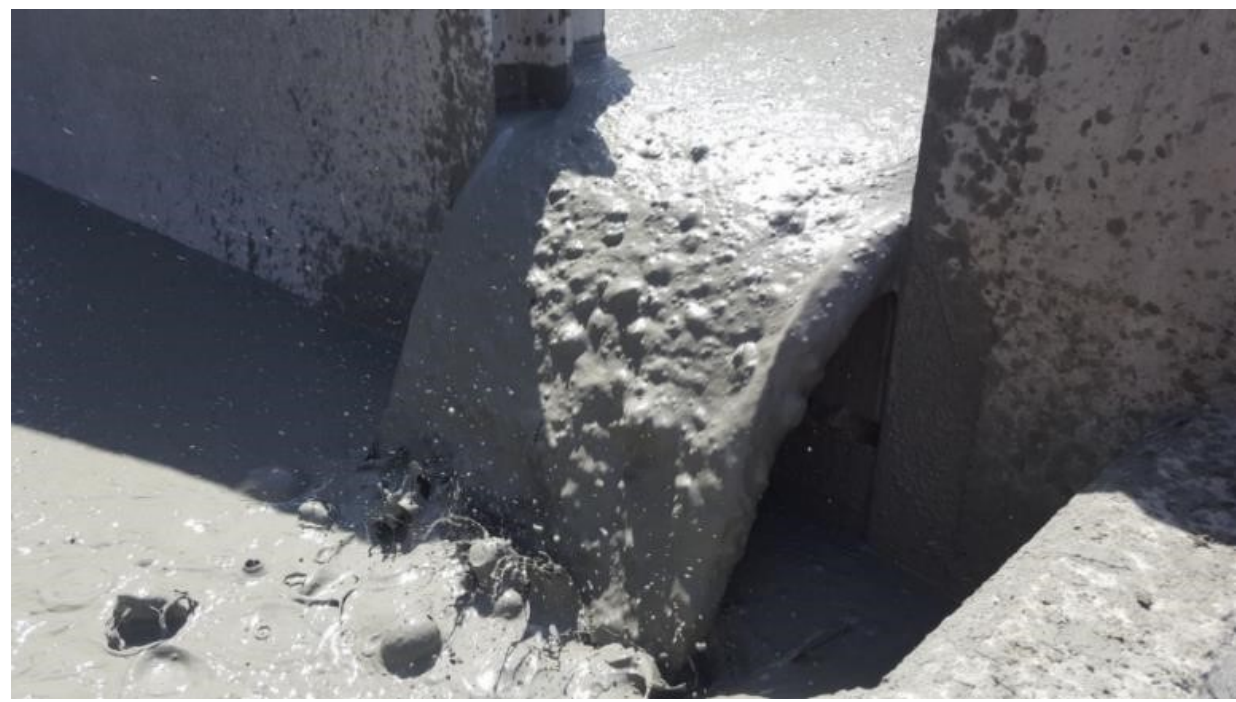

(b)

Figure 11 Lumps in (a) Tailings stockpiles; (b) Paste during commissioning

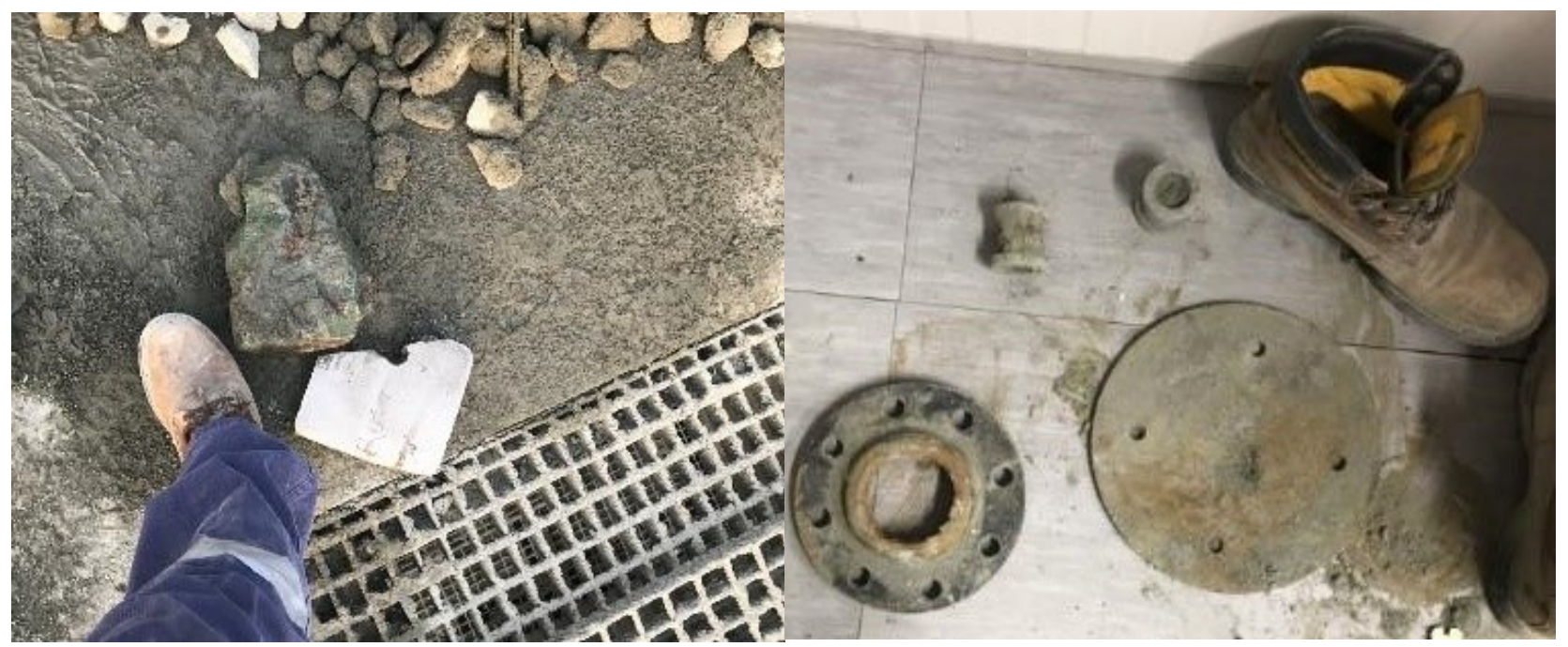

Figure 12 Rocks in filter cake and foreign material caught by screen 
Strict controls around blast procedures at Jabal Sayid also led to a different approach to emergency pressure relief during plugged line situations. Typical blast spools could not be used and so the mine improvised with a 'yank' tee (Figure 13) that gets pulled by winch and cable to open the line remotely and relieve pressure if there is ever a plug.

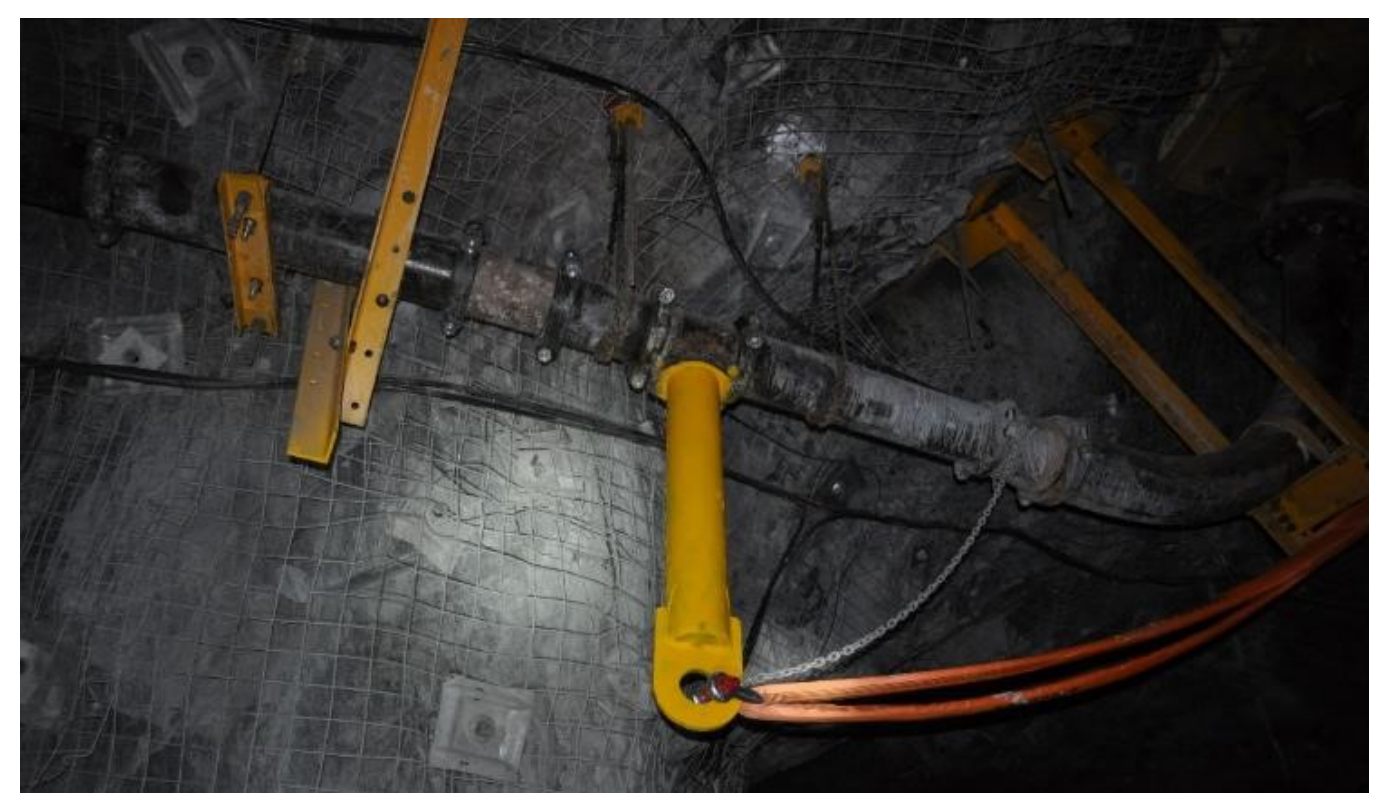

Figure 13 Jabal Sayid 'yank' tee for remote pressure release

\section{$9 \quad$ Results}

By investing the required capital in designing and constructing a plant with surplus capacity, maintaining close supervision and training through commissioning and investing in engineering fail-safes and extensive monitoring systems, MBCC ensured that full-scale paste production was achieved in a suitable time frame. Though not without commissioning issues, such as line blockages, mechanical redesigns and tailings feed consistency issues, the conservative throughput of the plant allowed for the reduction of the void backlog by $233,000 \mathrm{~m}^{3}$ in the first seven months of operating while maintaining full mining production (Figure 14). Going forward, the plant is forecast to run at or below its design capacity, while successfully moving the bottleneck of the mining cycle back onto stope production, the goal of any backfill plant.

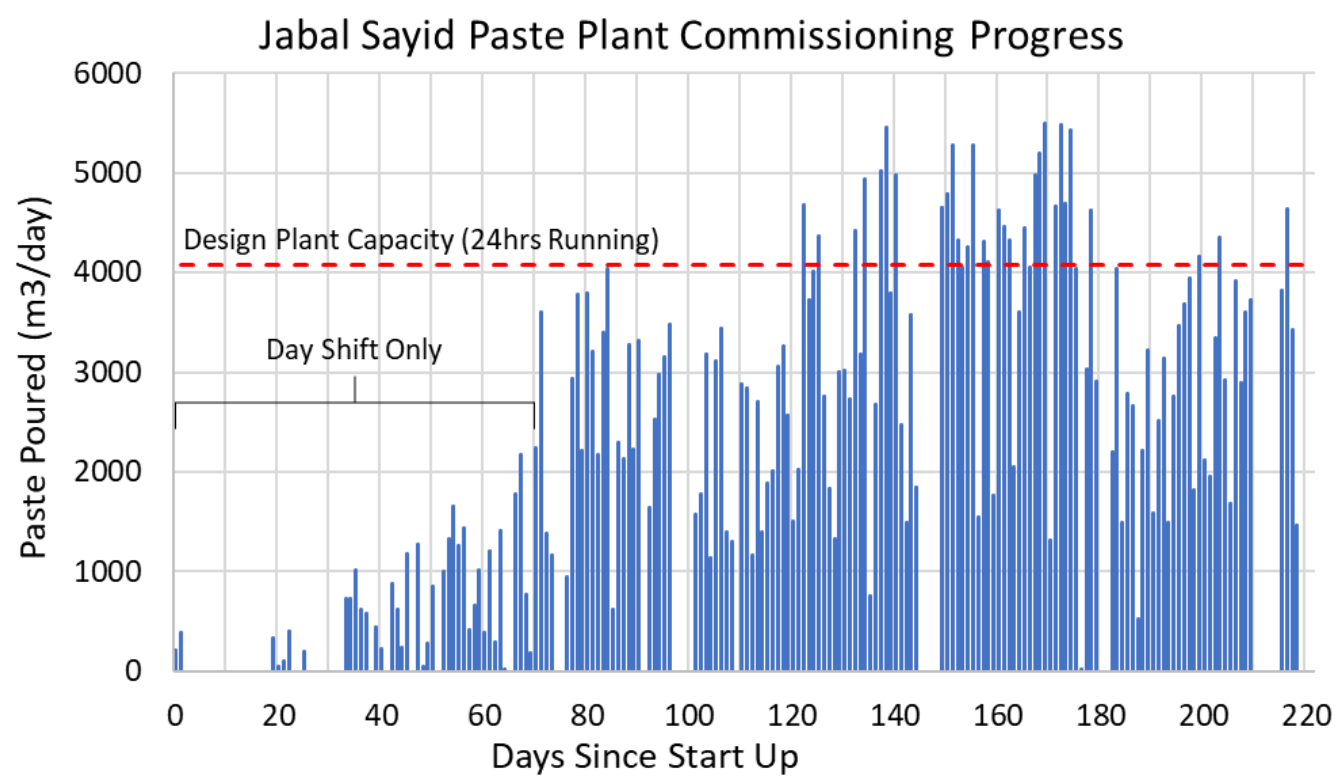

Figure 14 Jabal Sayid paste backfill production profile 


\section{Conclusion}

Paste backfill has been a huge success at Jabal Sayid, both from a water management and a mining cycle perspective. The investment made in benchmarking and expertise within Barrick and consultants was essential in steering the project to a safe and successful start-up. Sticking with the goal of high throughput, even while under pressure to reduce capital, has kept the backfill plan ahead of the mining schedule.

Along the way, a mix of ex-patriot experience and local help has ensured a sustainable solution through knowledge transfer to national operators who now run the system and complete their own QA/QC. The investment in technology and instrumentation has allowed for educated decisions to be made going forward. This includes monitoring of paste rheology, adjustments to fines and coarse blend ratios, live-feed cameras on all stopes, pressure indicators and real-time barricade monitoring.

It is important to note that the original paste testing and design work led to knowledgeable and conservative design as a starting point. Now, months after start-up and the first year of operation, there is a never-ending process of continual improvement that takes place to steadily increase reliability and utilisation while always pursuing lower operating costs. Over the next year, the mine intends to study further binder reduction, control the variability of PSD, reworking of fines material and extended delivery ranges underground.

\section{Reference}

Ellyatt, H \& Gamble, H 2018, 'Goodbye oil, Saudi Arabia's future economic growth will come from its mega-cities', CNBC, 23 January, accessed August 2018. 
